\title{
The combination of the histone-deacetylase inhibitor trichostatin A and gemcitabine induces inhibition of proliferation and increased apoptosis in pancreatic carcinoma cells
}

\author{
SUSANNE GAHR, MATTHIAS OCKER, MARION GANSLMAYER, STEFFEN ZOPF, KINYA OKAMOTO, \\ ANDREA HARTL, SANDRA LEITNER, ECKHART G. HAHN and CHRISTOPH HEROLD \\ Department of Medicine I, University Hospital Erlangen, Ulmenweg 18, D-91054 Erlangen, Germany
}

Received January 19, 2007; Accepted April 16, 2007

\begin{abstract}
The prognosis of advanced pancreatic cancer is poor. Established chemotherapy shows only limited efficacy and significant side effects. We investigated how far a combination of trichostatin A (TSA) and gemcitabine synergizes to inhibit proliferation and promotion of apoptosis of pancreatic adenocarcinoma cells in vitro. The human pancreatic carcinoma cells YAPC, DANG and Panc-89 and primary human foreskin fibroblasts as non-malignant controls were cultured under standardized conditions and incubated with gemcitabine und TSA alone $\left(10^{-4}\right.$ to $\left.10^{-8} \mathrm{M}\right)$ or together $\left(10^{-6}\right.$ to $\left.10^{-7} \mathrm{M}\right)$. After 24-72 $\mathrm{h}$ the apoptotic rate was analyzed by flow cytometry (propidium iodide, FACS). DNA-synthesis was assessed using bromodeoxyuridine (BrdU) incorporation. Protein was separated for Western blotting against caspase-3 and $-8, \mathrm{p} 21$, bax and bcl-2. The combination of TSA und gemcitabine leads to better pro-apoptotic effects than the employment of single substances. Bcl-2, a mitochondrial protein, which protects against apoptosis, was not expressed. Bax, an apoptosis inducing protein, which destabilizes the mitochondrial membrane potential, was increasingly expressed. Combination of TSA and gemcitabine shows promise for treatment of pancreatic cancer in vivo.
\end{abstract}

\section{Introduction}

Pancreatic cancer has a very poor prognosis with 1-year and 5 -year relative survival rates of 2 and $4 \%$, respectively and is the 4th and 5th leading cause of cancer death for men and women, respectively (1). The incidence is rising and the

Correspondence to: Dr Christoph Herold, Department of Medicine I, University Hospital Erlangen, Ulmenweg 18, D-91054 Erlangen, Germany

E-mail: christoph.herold@med1.imed.uni-erlangen.de

Key words: pancreatic cancer, gemcitabine, trichostatin A, bax, caspase-8 disease primarily involves an older population with a peak incidence in the 6th decade. Tumors predominantly evolve from exocrine pancreas and are adenocarcinomas in $95 \%$ of cases. Unfortunately, most patients are diagnosed at advanced tumor stages with metastasis already in distant organs. Diagnosed at an advanced stage, curative surgery is no longer possible. Even for those patients diagnosed with local stage disease, the 5-year relative survival rate is only $17 \%$ (1). Altough there is evidence that chemotherapy improves qualitiy of life and survival, the dimension of that effect, which ameliorates clinical status, is negligible. The results of cytotoxic chemotherapy have been very disappointing. Gemcitabine has only limited measurable antitumor efficacy, with response rates of $<10 \%$ and a median survival of $<6$ months (2).

Histone deacetylase is recognized as one of the most promising targets for cancer treatment. Many histone deacetylase inhibitors (HDACi) were successfully used to inhibit cell growth of different human carcinoma cells (3-5). Histones are basic proteins that form complexes with DNA called nucleosomes, resulting in the compact structure of chromatin. Basic amino acids of the histones can be modified posttranslationally with ubiquitin or with methyl-, acetyl- or phosphate groups. Acetylation of lysine residues of histones weakens their binding to DNA and induces a change of DNA conformation which is essential for binding of transcription factors to the promoter regions of, e.g. cell cycle regulatory genes $(6,7)$. A positive association between highly expressed genes and the grade of histone-acetylation in the respective promoter gene loci was reported (8). Histone deacetylation may repress transcription by strengthening histone-DNA interaction and thereby blocking the access of transcription regulators to the DNA template. Histone-deacetylase inhibitors have been reported to induce $G_{1}$ or $G_{2}$ phase arrest, and regulate the transcription of a number of cell cycle regulator genes, including p21, c-myc, cyclins and cdks. TSA can induce apoptosis in highly proliferative cells such as lymphocytes and various carcinoma cells at low concentrations $\left(10^{-7}\right.$ to $\left.10^{-12} \mathrm{M}\right)(3,5,7,9)$. Besides affecting the expression of proteins regulating progression of the cell cycle, TSA modulates regulators of apoptosis, such as caspases (7). Until 
now the effect of HDACi combinated with chemo-therapy on pancreatic carcinoma cells has been explored in a few experiments only, without investigating possible signal transduction pathways (10). However, the combination of HDACi and chemotherapeutic agents was successful in hepatoma cells (11). Therefore, we investigated the effect of TSA and gemcitabine on proliferation, apoptosis and especially on the apoptotic pathways of pancreatic carcinoma cells.

\section{Materials and methods}

Reagents and cell culture. YAPC, DANG and PANC-89 pancreatic adenocarcinoma cells as well as human foreskin fibroblasts (HF) were cultured on 6-well tissue culture plates or 96-well plates (Becton-Dickinson, Mannheim, Germany) in RPMI-1640 medium (Biochrom, Berlin, Germany) containing $10 \%$ fetal bovine serum (FBS, Gibco-BRL, Karlsruhe, Germany), penicillin ( $10^{7} \mathrm{U} / 1$, Biochrom) and streptomycin $\left(10 \mathrm{mg} / \mathrm{l}\right.$, Biochrom) at $37^{\circ} \mathrm{C}$ and $5 \% \mathrm{CO}_{2}$. All cell lines were obtained from the German Collection of Microorganisms and Cell Cultures (DSMZ; Braunschweig, Germany). HF cells as non-malignant controls were used, because primary pancreatic duct cells are very difficult to maintain and are unstable under standard cell culture conditions.

TSA was purchased from Sigma (Deisenhofen, Germany) and gemcitabine was obtained from Lily (Bad Homburg, Germany). For the experiments, gemcitabine was dissolved in dimethyl sulfoxide (DMSO, 0.5\%, Sigma), TSA was dissolved in Dulbecco's modified Eagle's medium (DMEM, Biochchrom) containing 10\% fetal bovine serum and also $0.5 \%$ DMSO. Further dilutions to concentrations of $10^{-4}$ to $10^{-8} \mathrm{M}$ were done using complete cell culture medium.

Flow cytometric analysis of apoptosis. Cells were starved for $24 \mathrm{~h}$ in medium containing $0.125 \%$ FBS to achieve cell cycle synchronization and then washed twice with phosphatebuffered saline (PBS, Biochrom), treated with trypsin EDTA ( $0.05 \%$ trypsin, $0.02 \%$ EDTA, Biochrom), seeded at a density of $0.5 \times 10^{6}$ per well and incubated for $12,24,48$ or $72 \mathrm{~h}$ in the presence of TSA or gemcitabine alone or in combination. For quantification of apoptosis, cells were washed twice with PBS, trypsined and lysed in a hypotonic solution containing $0.1 \%$ sodium citrate, $0.1 \%$ Triton $\mathrm{X}-100$ and $50 \mu \mathrm{g} / \mathrm{ml}$ propidium iodide (Sigma). Analysis of labelled nuclei was performed on a FACSCalibur fluorescence-activated cell sorter (FACS) using CELLQuest software (both from BectonDickinson, Heidelberg, Germany). The percentage of apoptotic cells was determined by measuring the fraction of nuclei with a sub-diploid DNA content. Ten thousand events were collected for each sample analysed.

Determination of DNA-synthesis. DNA-synthesis as a marker for cellular proliferation was measured by bromodeoxyuridine (BrdU) incorporation using the Cell Proliferation ELISA (Roche Molecular Biochemicals, Mannheim, Germany) based on incorporation of BrdU into newly synthesized DNA and antibody-mediated detection of BrdU in DNA, as described before (11).
Analysis of mitochondrial membrane potential. Mitochondrial injury was assessed by JC-1 (5,5',6,6'-tetrachloro1,1',3,3'-tetraethybenzimidazolocarbocyanine iodide) staining (Sanova Pharma GmbH, Vienna, Austria). This dye, which exists as a monomer in solution emitting a green fluorescence $(537 \mathrm{~nm})$, can assume a dimeric configuration emitting red fluorescence $(597 \mathrm{~nm})$ in a reaction driven by the mitochondrial transmembrane potential. Thus, red fluorescence of JC-1 indicates intact mitochondria, whereas green fluorescence shows monomeric JC-1 that has remained unprocessed due to breakdown of the mitochondrial membrane potential $\Delta \Psi_{\mathrm{m}}$ (12). Cells were adjusted to a density of $0.2 \times 10^{6} / \mathrm{ml}$ trypsinized, washed in PBS, resuspended in $1 \mathrm{ml}$ medium, and stained with $5 \mu \mathrm{g} / \mathrm{ml} \mathrm{JC}-1$ for $15 \mathrm{~min}$ at $37^{\circ} \mathrm{C}$ in an atmosphere containing $5 \% \mathrm{CO}_{2}$ in the dark, then washed twice in PBS and resuspended in $0.5 \mathrm{ml}$ PBS. Analysis was performed by FACS scan and mitochondrial function was assessed as JC-1 green (uncoupled mitochondria, detector FL-2) fluorescence (12-14). For quadrant analysis, 10,000 events were collected and gated for cell viability according to the FSC-SSC plot.

Immunohistological assessment of apoptosis. Cleavage of cytokeratin 18 by activated caspase- 3 and -7 reveals a neoepitope that is specifically recognized by the M30 antibody (CytoDeath, Roche Molecular Biochemicals). The generation of this neo-epitope is an early event in apoptosis, occurring before cells become positive for annexin V or TUNEL staining. It has been shown that the M30 epitope is not present in nonapoptotic cells or tissues (15). Cells were stained according to the manufacturer's instructions after $24 \mathrm{~h}$ of incubation with TSA and gemcitabine. Analysis was performed on a Zeiss Axioplan fluorescence microscope (Carl Zeiss, Göttingen, Germany) with OpenLab software (Improvision, Heidelberg, Germany).

Assessment of caspase-3 and -8. The Caspase Colorimetric Assay (R\&D Systems, Minneapolis, MN) was used to determine the enzymatic activity of caspases- 3 and -8 . The assays were performed according to the manufacturer's instructions after 24 to $72 \mathrm{~h}$ of incubation with TSA and gemcitabine in combination $\left(10^{-6}\right.$ to $\left.10^{-7} \mathrm{M}\right)$. Caspase activation leads to the cleavage of the provided colorimetric substrates conjugated to Q-nitroaniline (DVED-@NA for caspase-3 or IETD-@NA caspase-8) and can be measured photometrically at $405 \mathrm{~nm}$.

Western blot analysis of proteins involved in apoptosis. Trypsined and washed cells were lysed by adding $100 \mu 12 \mathrm{X}$ sample buffer (2 mM NEM, 2 mM PMSF, 4\% SDS, 4\% DTT, $20 \%$ glycerol, $0.01 \%$ bromophenol blue, $2 \mathrm{M}$ urea, $0.01 \mathrm{M}$ Na-EDTA, $0.15 \mathrm{M}$ Tris- $\mathrm{HCl}$ ) to $10^{6}$ cells. DNA was sheared by pipetting up and down for $3 \mathrm{~min}$ at room temperature. Samples were boiled at $95^{\circ} \mathrm{C}$ for $15 \mathrm{~min}$, centrifuged at $13,000 \mathrm{pm}$ for $10 \mathrm{~min}$ and then subjected to $14 \%$ SDS-PAGE (precast gels; Invitrogen, Karlsruhe, Germany). After blocking overnight at $4^{\circ} \mathrm{C}$ in a buffer containing PBS, $0.1 \%$ Tween-20 and 4\% low-fat milk powder, nitrocellulose membranes were incubated for 90 min with polyclonal mouse anti-human Bcl-2 (1:500, BD), polyclonal rabbit anti- 
Table I. Percent apoptosis quantified by flow cytometric cell cycle analysis after propidium iodide staining after 72-h treatment with TSA (0.1-10 $\mu \mathrm{M})$ and gemcitabine (0.1-10 $\mu \mathrm{M})$.

\begin{tabular}{|c|c|c|c|}
\hline Apoptosis & DANG & YAPC & Panc-89 \\
\hline TSA $10^{-6} \mathrm{M}$ & $71 \pm 2.6^{\mathrm{b}}$ & $66 \pm 2.0^{\mathrm{b}}$ & $49 \pm 12.1^{b}$ \\
\hline TSA $10^{-5} \mathrm{M}$ & $92 \pm 1.6^{\mathrm{b}}$ & $82 \pm 1.0^{\mathrm{b}}$ & $81 \pm 12.2^{b}$ \\
\hline G $10^{-6} \mathrm{M}$, TSA $10^{-6} \mathrm{M}$ & $98 \pm 0.3^{b}$ & $89 \pm 0.7^{b}$ & $74 \pm 1.7^{b}$ \\
\hline G $10^{-7} \mathrm{M}, \mathrm{TSA} 10^{-7} \mathrm{M}$ & $74 \pm 1.2^{\mathrm{b}}$ & $22 \pm 1.5^{b}$ & $6.0 \pm 04^{\mathrm{b}}$ \\
\hline G $5 \times 10^{-7} \mathrm{M}$, TSA $5 \times 10^{-7} \mathrm{M}$ & $89 \pm 0.2^{b}$ & $64 \pm 2.6^{b}$ & $24 \pm 1.5^{b}$ \\
\hline $\mathrm{G} 10^{-7} \mathrm{M}, \mathrm{TSA} 10^{-6} \mathrm{M}$ & $97 \pm 1.2^{\mathrm{b}}$ & $56 \pm 2.1^{b}$ & $53 \pm 1.1^{\mathrm{b}}$ \\
\hline Control & $1.8 \pm 0.2$ & $4.8 \pm 0.1$ & $2.9 \pm 0.3$ \\
\hline
\end{tabular}

Results are means \pm SD of 3 independent experiments. ${ }^{\mathrm{a}} \mathrm{p} \leq 0.05$ vs. untreated cells; ${ }^{b} \mathrm{p} \leq 0.01 \mathrm{vs}$. untreated cells.

human Bax (1:500, sc-493, both Santa Cruz Biotechnology, Santa Cruz, CA), polyclonal rabbit anti-human caspase- 8 $(1: 1,000)$, polyclonal mouse anti-human caspase-3 (1:1000, both BD, p21 1:500, BD) or B-actin (1:5000, Sigma) antibodies. Membranes were washed twice for $10 \mathrm{~min}$ in a buffer containing PBS, $0.1 \%$ Tween-20 and 4\% low-fat milk powder and incubated with an anti-rabbit or anti-mouse IgG coupled to peroxidase $(1: 1,000$, Sigma) for $1 \mathrm{~h}$ at room temperature. Reactive bands were detected with the ECL chemiluminescence reagent (Amersham Pharmacia Biotech, Freiburg, Germany) using a Fluor-Chem 8900 digital image analyser (AlphaInnotech, San Leandro, CA). Densitometric analysis was performed using Gelscan 5.01 (BioSciTec, Frankfurt, Germany). Values were normalized to $B$-actin levels and are shown as changes relative to untreated cells.

Statistical analysis. Statistical analysis was performed using Excel for Windows. Significant differences were calculated using the t-test for paired samples. P-values of $\leq 0.05$ were regarded as significant and those $\leq 0.01$ as highly significant.

\section{Results}

Combination of gemcitabine and TSA induces apoptosis in pancreatic cancer cells. The effect of different TSA and gemcitabine concentrations alone $\left(10^{-4}\right.$ to $\left.10^{-8} \mathrm{M}\right)$ or together $\left(10^{-6}\right.$ to $\left.10^{-7} \mathrm{M}\right)$ on YAPC, DANG and PANC-89 pancreatic adenocarcinoma cell apoptosis was determined by flow cytometry (propidium iodide, FACS). The following described FACS data refer exemplary to YAPC cells. Similar results were obtained in the other cell types (Table I). Maximal induction of apoptosis with gemcitabine was seen at $10^{-5} \mathrm{M}$. Higher concentrations $\left(10^{-4} \mathrm{M}\right)$ did not show further increase, while concentrations below $10^{-7} \mathrm{M}$ were ineffective. Flow cytometry showed also a time-dependent increase of apoptosis. After incubation for $24 \mathrm{~h}$, apoptosis was increased to $10 \%$, whereas after incubation for 48 and $72 \mathrm{~h}$ there was an increase to 50 and $70 \%$, respectively. Treatment with a concentration of $10^{-6} \mathrm{M}$ increased apoptosis
A

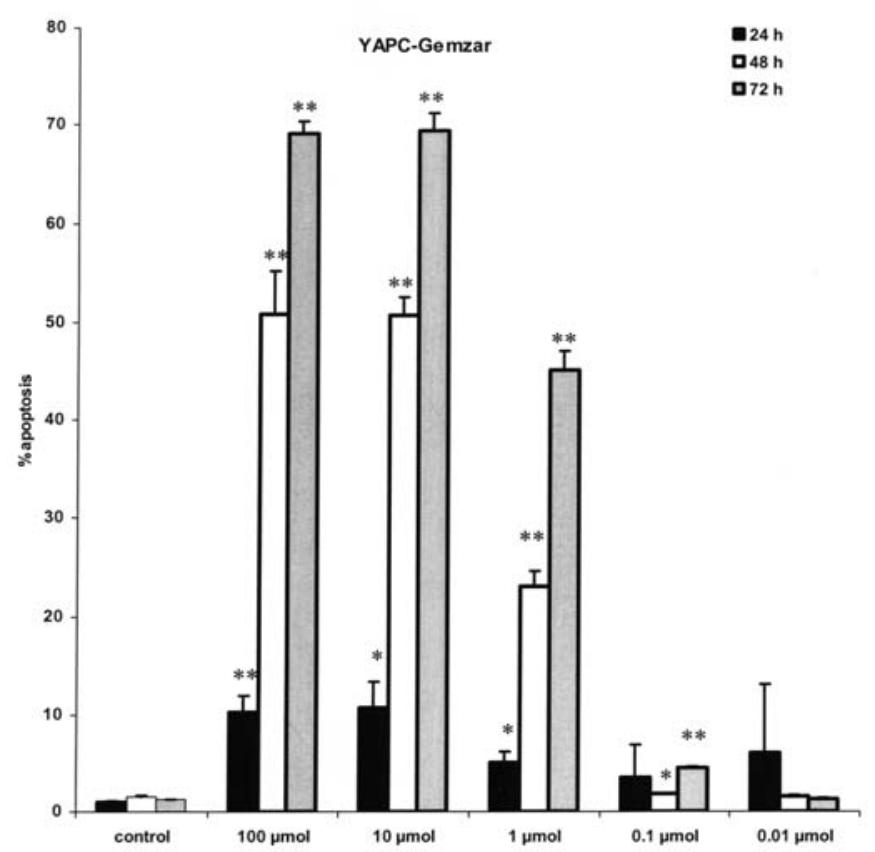

B

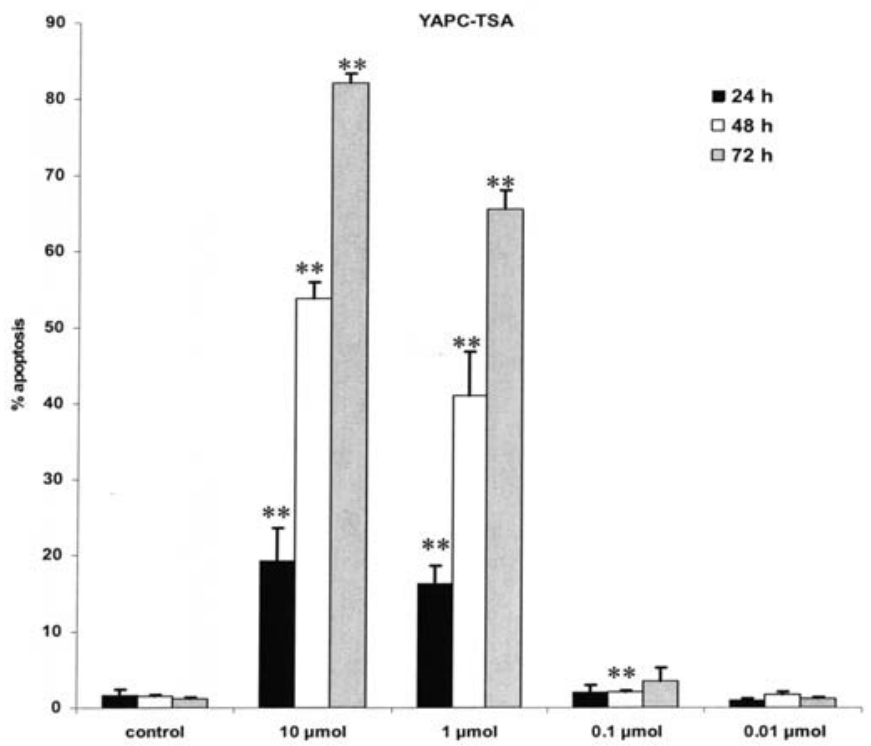

C

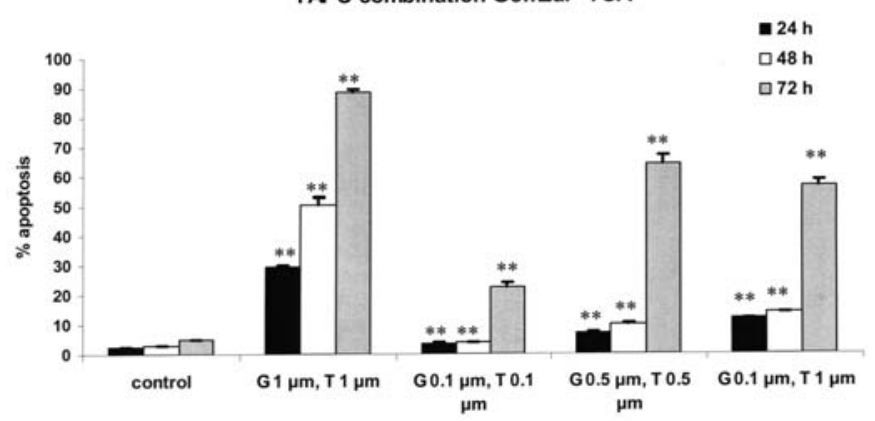

Figure 1. Induction of apoptosis in YAPC by gemcitabine treatment (A), TSA treatment (B) and combined treatment of TSA and gemcitabine (C) is time- and dose-dependent. Shown are apoptosis rates measured by flowcytometric analysis of sub-diploid nuclei stained with propidium iodide after incubation with gemcitabine or TSA alone or in combination over a time course of 24-72 h. Results are means \pm SD of 3 independent experiments. ${ }^{*} \mathrm{p} \leq 0.05$ vs. untreated cells; ${ }^{* *} \mathrm{p} \leq 0.01$ vs. untreated cells. 


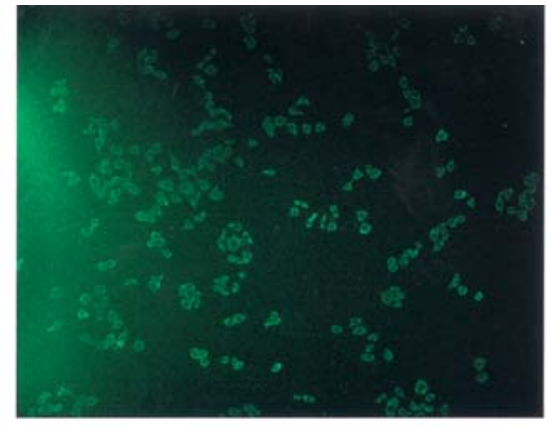

C

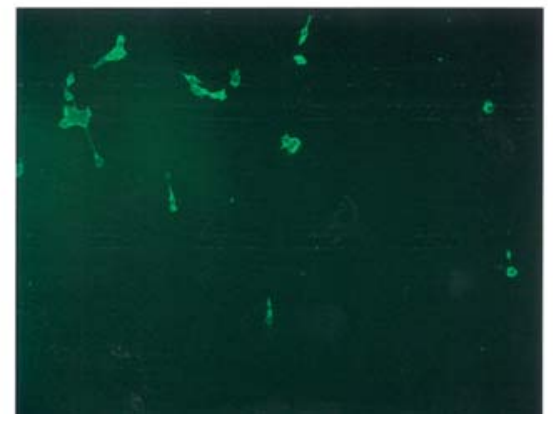

$B$

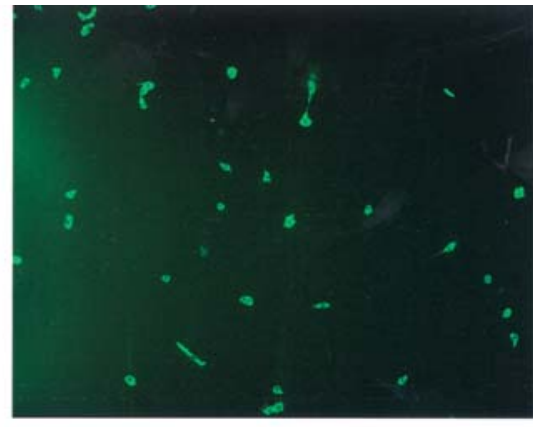

D

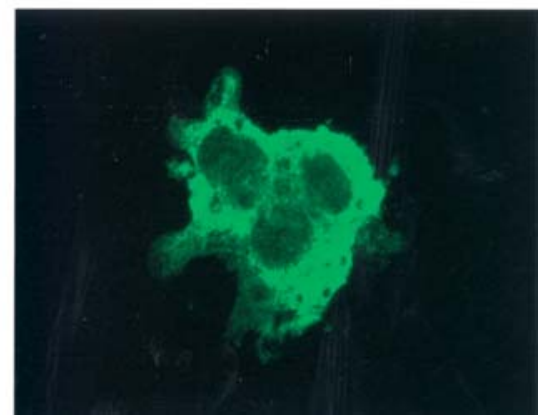

Figure 2. Immunofluorescence staining of apoptotic cytokeratin 18 cleavage. (B and C) Representative examples of Panc-89 cells treated with TSA (1 $\mu$ M) and gemcitabine $(1 \mu \mathrm{M})$ for $24 \mathrm{~h}$ (x1000) (B) and $72 \mathrm{~h}$ (x10) (C) (x40) (D). (A) Untreated control cells (x10). Apoptotic cells exhibit bright fluorescence, while vital cells show only background fluorescence.

\section{Control}
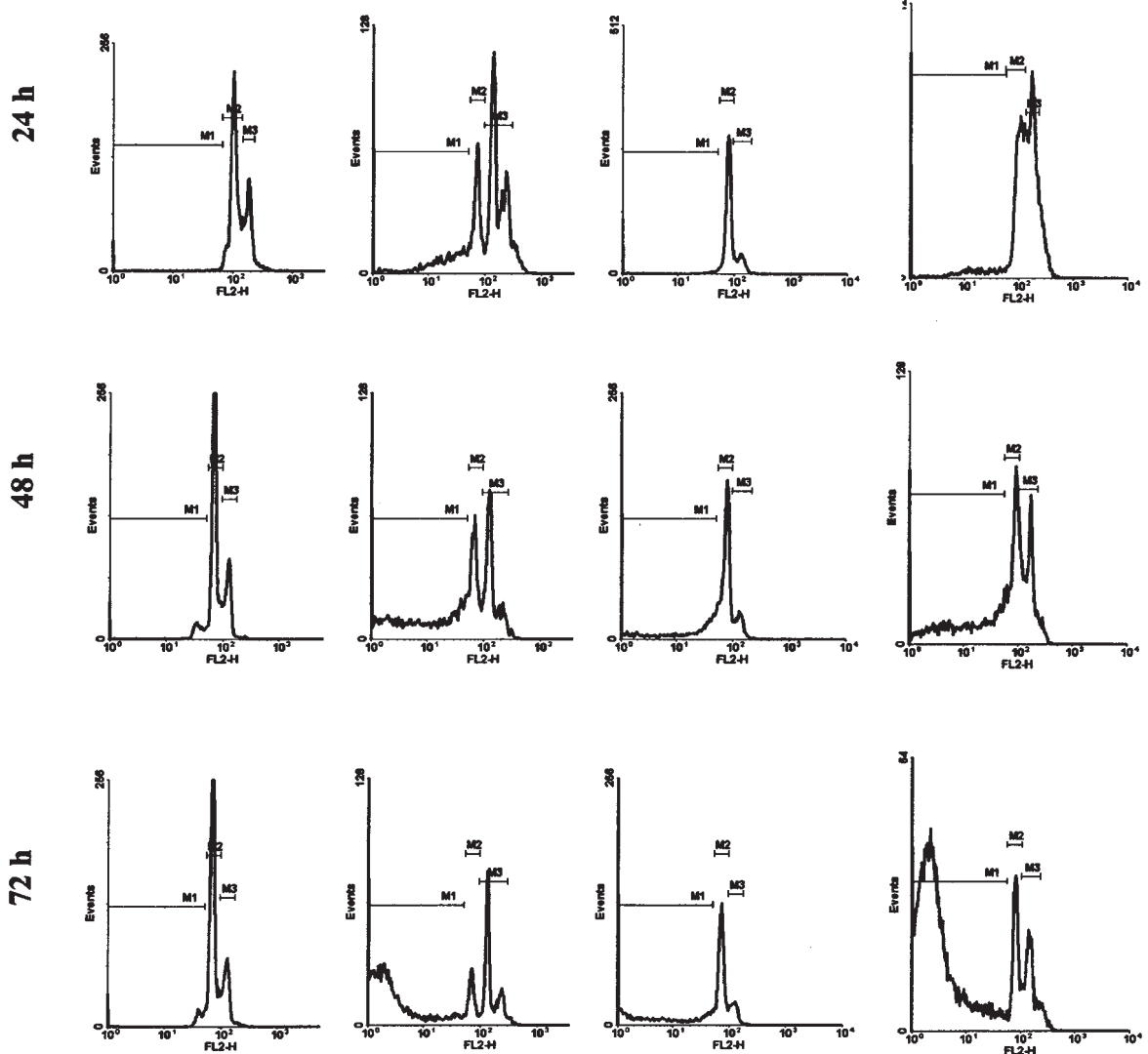

$1 \mu \mathrm{M}$ TSA

$1 \mu \mathrm{M}$ Gem

$1 \mu \mathrm{M}$ TSA/Gem
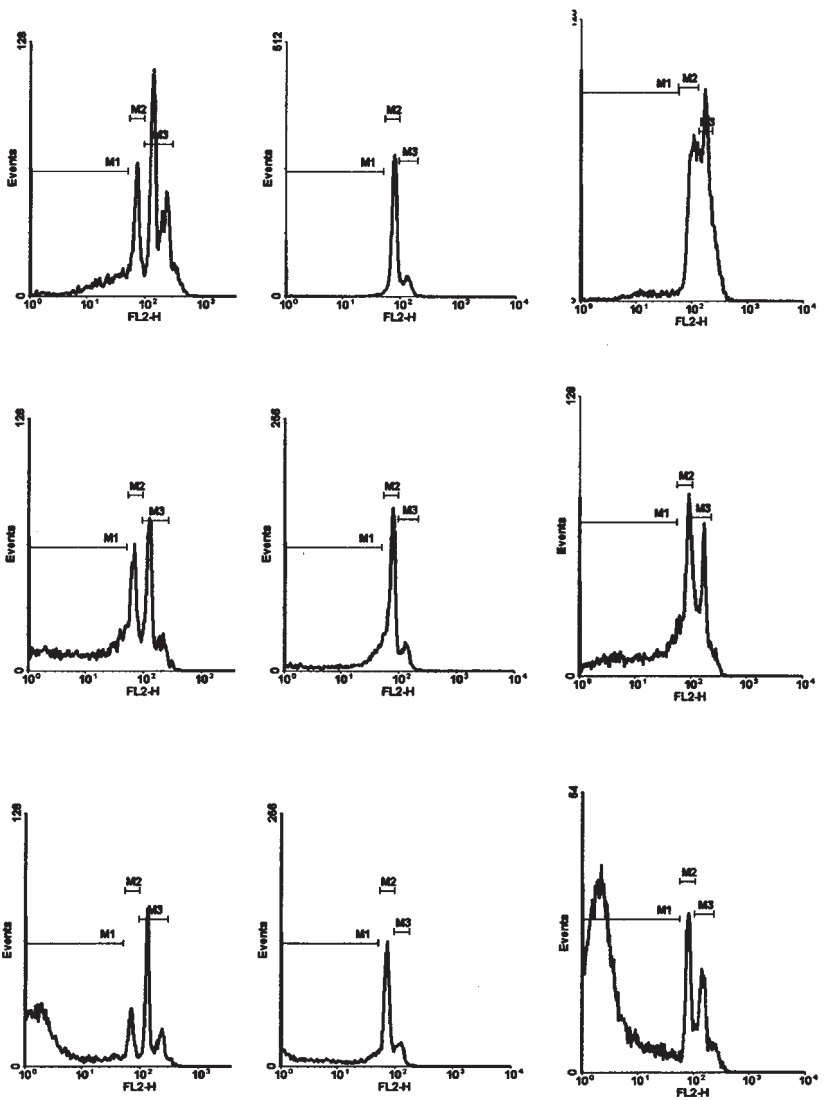

Figure 3. Flow cytometric cell cycle analysis after propidium iodide staining of YAPC cells cultured without and with TSA $(1 \mu \mathrm{M})$, gemcitabine $(1 \mu \mathrm{M})$ and in combination. Cells were treated for 24, 48 and $72 \mathrm{~h}$. Treatment with combination of TSA and gemcitabine disrupted the cell cycle after 48 and $72 \mathrm{~h}$, while treatment with gemcitabine alone showed no apoptotic effect. M1, apoptosis; M2, G1-phase; M3, synthesis/G - $_{2}$ phase; FL2-H, red fluorescence = DNAcontent after propidium iodide staining. 


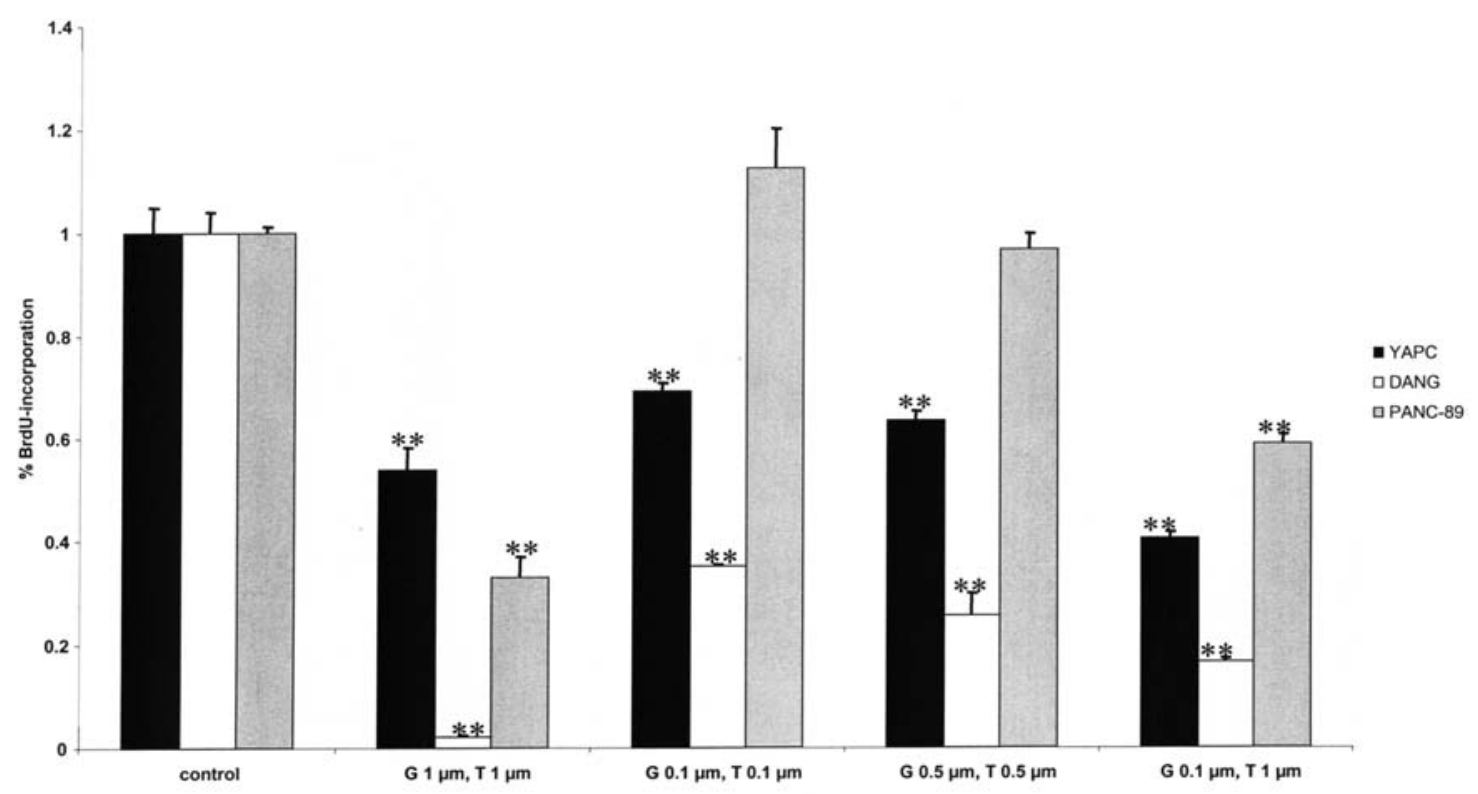

Figure 4. Inhibition of DNA-synthesis in YAPC, DANG and PANC-89. DNA-synthesis was measured by BrdU-incorporation after 24-h incubation with combination of different concentrations of TSA and gemcitabine. For untreated cells results were set at 1.0 . Results are means \pm SD of three independent experiments. ${ }^{* *} \mathrm{p} \leq 0.01$ vs. untreated cells.

from $4.5 \%(24 \mathrm{~h})$ to $45 \%(72 \mathrm{~h})$ (Fig. 1A). Incubation with TSA alone $\left(10^{-5}\right.$ to $\left.10^{-8} \mathrm{M}\right)$ showed a higher effect compared to gemcitabine. Maximal apoptosis was seen at a concentration of $10^{-5} \mathrm{M}$. The increase of apoptosis was, like incubation with gemcitabine, also time-dependent. After 24-h incubation apoptosis was increased to $19 \%$, after 48 and $72 \mathrm{~h}$ apoptosis increased from 54 to $82 \%$. A successful effect was even seen by a concentration of $10^{-6} \mathrm{M}$. Incubation for $24 \mathrm{~h}$ increased apoptosis to $16 \%$, an incubation over 48 and $72 \mathrm{~h}$ showed a further increase to 41 and $65 \%$. Concentrations below $10^{-7} \mathrm{M}$ were, like gemcitabine, ineffective (Fig. 1B). The control cell line (human foreskin fibroblasts, $\mathrm{HF}$ ) showed a clearly lower rate of apoptosis than the pancreatic carcinoma cells: $10^{-6} \mathrm{M}$ gemcitabine led to $6 \%$ apoptosis after $24 \mathrm{~h}, 7 \%$ apoptosis after $48 \mathrm{~h}$ and $23 \%$ apoptosis after $72 \mathrm{~h}$. In time-course experiments treatment with TSA $\left(10^{-6} \mathrm{M}\right)$ from 24 to $72 \mathrm{~h}$ increased apoptosis only from 4 to $8 \%$ (data not shown). Higher concentrations of gemcitabine as well as TSA led to a higher rate of apoptosis. Therefore, following experiments with combinations of gemcitabine and TSA were prepared with concentrations of $10^{-6} \mathrm{M}$ and below. The highest effect of apoptosis was shown by a concentration of $10^{-6} \mathrm{M}$ TSA and gemcitabine. In timedependent experiments, incubation for $24 \mathrm{~h}$ increased apoptosis to $29 \%$, further incubation for 48 and $72 \mathrm{~h}$ led to an increased rate of apoptosis from 50 to $89 \%$. Reduction of gemcitabine to a concentration of $10^{-7} \mathrm{M}$ induced a decreased apoptosis: for $24 \mathrm{~h}$ only $12 \%$ apoptosis, for $48 \mathrm{~h} 14 \%$ and for $72 \mathrm{~h} 56 \%$. At a combination of TSA $5 \times 10^{-7} \mathrm{M}$ and gemcitabine $5 \times 10^{-7} \mathrm{M}$ a similar effect was seen to TSA $10^{-6} \mathrm{M}$ combinated with gemcitabine $10^{-7} \mathrm{M}$ : after 24-h incubation an apoptosis rate of $7 \%$, after $48 \mathrm{~h} 10 \%$ and after $72 \mathrm{~h} 64 \%$. The combination of gemcitabine and TSA, both at $10^{-7} \mathrm{M}$ increased apoptosis to $22 \%$ only after an incubation of $72 \mathrm{~h}$ (Fig. 1C).
Increased cleavage of cytokeratin 18 by TSA and gemcitabine. Verification of apoptosis by immunofluorescence staining of cytokeratin 18 cleveage fragments showed a marked increase in positively stained cells with morphologic signs of apoptosis after treatment with TSA and gemcitabine in combination. In untreated controls only background fluorescence and a few positive cells, a significant increase, was detected (Fig. 2).

Combination of gemcitabine and TSA inhibits cell cycle progression and DNA synthesis. Cell cycle analysis revealed a TSA- and gemcitabine-induced $\mathrm{G}_{2} / \mathrm{M}$-phase arrest, which preceded apoptosis (Fig. 3). Cells incubated with TSA $\left(10^{-6} \mathrm{M}\right)$ entered $\mathrm{G}_{2} / \mathrm{M}$-phase arrest before cells incubated with gemcitabine $\left(10^{-6} \mathrm{M}\right)$. After $24 \mathrm{~h}$ of incubation with TSA $\left(10^{-6} \mathrm{M}\right) 48 \%$ of the YAPC cells were in $\mathrm{G}_{2} / \mathrm{M}$-phase (vs. $32 \%$ without TSA), whereas after $24 \mathrm{~h}$ of incubation with gemcitabine only $38 \%$ of the cells were in $\mathrm{G}_{2} / \mathrm{M}$-phase (vs. $36 \%$ without gemcitabine). The reason of a lower cell rate in the $\mathrm{G}_{2} / \mathrm{M}$-phase is that gemcitabine leads to an increased $\mathrm{G}_{1}$-arrest of the cell cycle.

BrdU-incorporation, which correlates with DNA-synthesis and proliferation, was determined in experiments using combinations between TSA and gemcitabine after testing the single substances (data not shown). Relative to untreated controls $(100 \%)$ incubation for $24 \mathrm{~h}$ with gemcitabine $\left(10^{-6} \mathrm{M}\right)$ and TSA $\left(10^{-6} \mathrm{M}\right)$ reduced proliferation by $46 \%$ (YAPC) $(\mathrm{p} \leq 0.01), 98 \%(\mathrm{DANG})(\mathrm{p} \leq 0.01)$ and $67 \%(\mathrm{PANC}-89)$ $(\mathrm{p} \leq 0.01)$. A further reduction of gemcitabine to a concentration of $10^{-7} \mathrm{M}$, but with maintaining a TSA concentration of $10^{-6} \mathrm{M}$, showed a reduction of the proliferation rate by $60 \%$ (YAPC) $(\mathrm{p} \leq 0.01), 83 \%$ (DANG) $(\mathrm{p} \leq 0.01)$ and $11 \%$ (PANC-89) $(\mathrm{p} \leq 0.01)$. Combination of TSA $5 \times 10^{-7} \mathrm{M}$ and gemcitabine $5 \times 10^{-7} \mathrm{M}$ or TSA $10^{-7} \mathrm{M}$ and gemcitabine $10^{-7} \mathrm{M}$ showed similar effects: $27 \%(\mathrm{p} \leq 0.01)$ and $30 \%(\mathrm{p} \leq 0.01)$ proliferation 

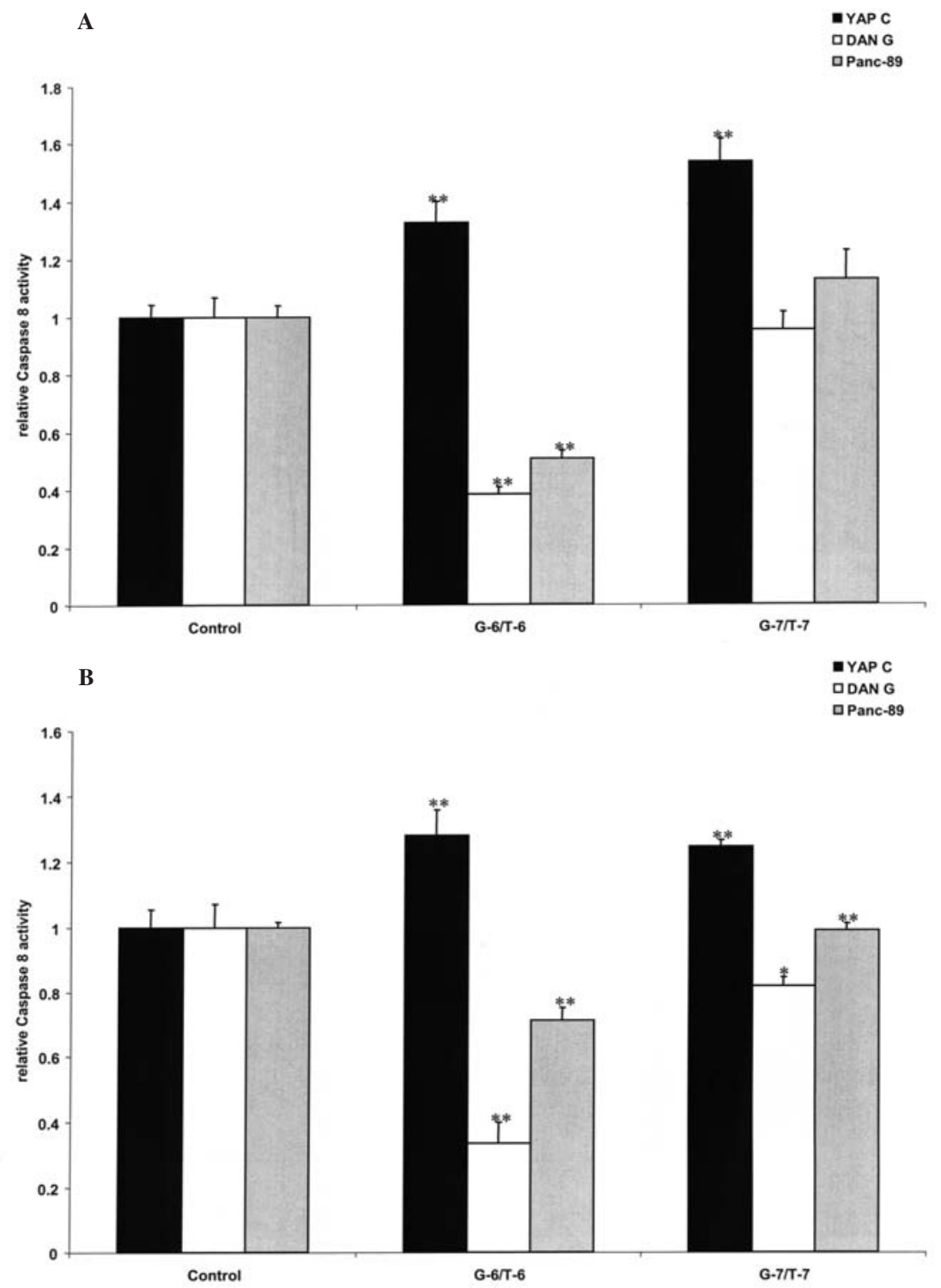

Figure 5. Assessment of caspase-8 activity in YAPC, DANG and PANC-89 cells after treatment with TSA and gemcitabine for $24 \mathrm{~h}$ (A) and $72 \mathrm{~h}$ (B) by a colorimetric substrate cleavage assay. Activity of caspase- 8 was set at 1.0 for untreated controls. Values for treated cells are expressed in relation to untreated control cells. Results are means \pm SD of three independent experiments. $p \leq 0.05$ vs. untreated cells; ${ }^{* *} p \leq 0.01$ vs. untreated cells.

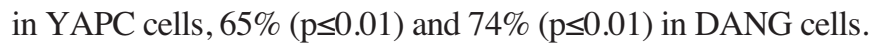
The same combination in PANC-89 cells were ineffective and did not decrease DNA-synthesis ( $\mathrm{p}>0.05$ ) (Fig. 4). Overall, combination treatment significantly decreased BrdU incorporation as compared to both single agents (data not shown).

The combination of gemcitabine and TSA induces a constantly high activation of caspase- 8 and bax. Incubation with TSA and gemcitabine in time-dependent experiments showed activation of following key proteins, which indicate apoptosis. Activity of caspase- 8 after 24 and 72 h was only seen in YAPC, not in DANG or PANC-89 (Fig. 5). In Western blot analysis, caspase- 8 levels were constantly expressed after 12 and $72 \mathrm{~h}$ in all tested adenocarcinoma cell lines (Fig. 7, data for YAPC not shown, but similar to results of DANG and PANC-89). The determination of the enzymatic activity of caspase- 3 after 24 and $72 \mathrm{~h}$ showed only a minor activation in DANG and no activation in PANC-89 cells and confirmed the Western blotting results. Only YAPC cells had concentration-independent increased enzymatic activity after $24 \mathrm{~h}$ as well as after $72 \mathrm{~h}$ (Fig. 6). Expression of the proapoptotic bax, an apoptosis inducing protein, which destabilizes the mitochondrial membrane potential, was constantly expressed on a high level in all adenocarcinoma cell lines (Fig. 7, exemplary data are given for $48 \mathrm{~h}$ ). Apoptotic p21 cip/waf (data not shown) was, as bcl-2, not detectable (Fig. 7).

Loss of $\Delta \Psi_{m}$ parallels induction of apoptosis. JC-1 experiments for the mitochondrial injury of the cells confirmed the results of Western blot analysis (Fig. 8). The mitochondrial membrane potential by JC- 1 staining showed that in YAPC cells about $92 \%(24 \mathrm{~h})$ and $95 \%(72 \mathrm{~h})$ of untreated control cells contained intact mitochondria, while combined therapy with $10^{-7} \mathrm{M}$ gemcitabine and $10^{-7} \mathrm{M}$ TSA reduced this level 
A $\quad \begin{array}{ll}\text { MYAPC } \\ \text { IDANG }\end{array}$

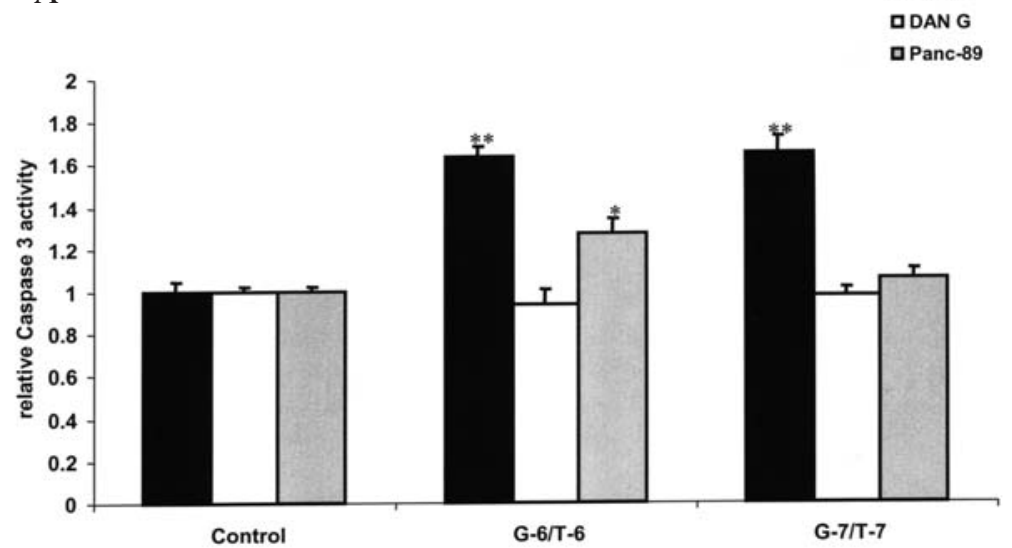

$\mathrm{B}$

a YAP C

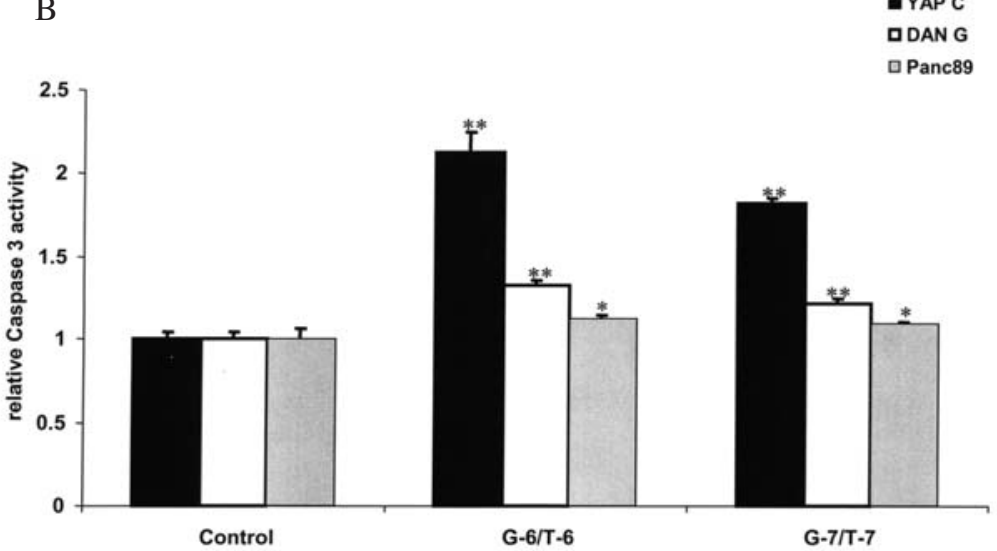

Figure 6. Assessment of caspase-3 activity in YAPC, DANG and PANC-89 cells after treatment with TSA and gemcitabine for $24 \mathrm{~h}$ (A) and $72 \mathrm{~h}$ (B) by a colorimetric substrate cleavage assay. Activity of caspase-3 was set at 1.0 for untreated controls. Values for treated cells are expressed in relation to untreated control cells. Shown are means \pm SD of three independent experiments. ${ }^{*} \mathrm{p} \leq 0.05$ vs. untreated cells; ${ }^{* *} \mathrm{p} \leq 0.01$ vs. untreated cells.

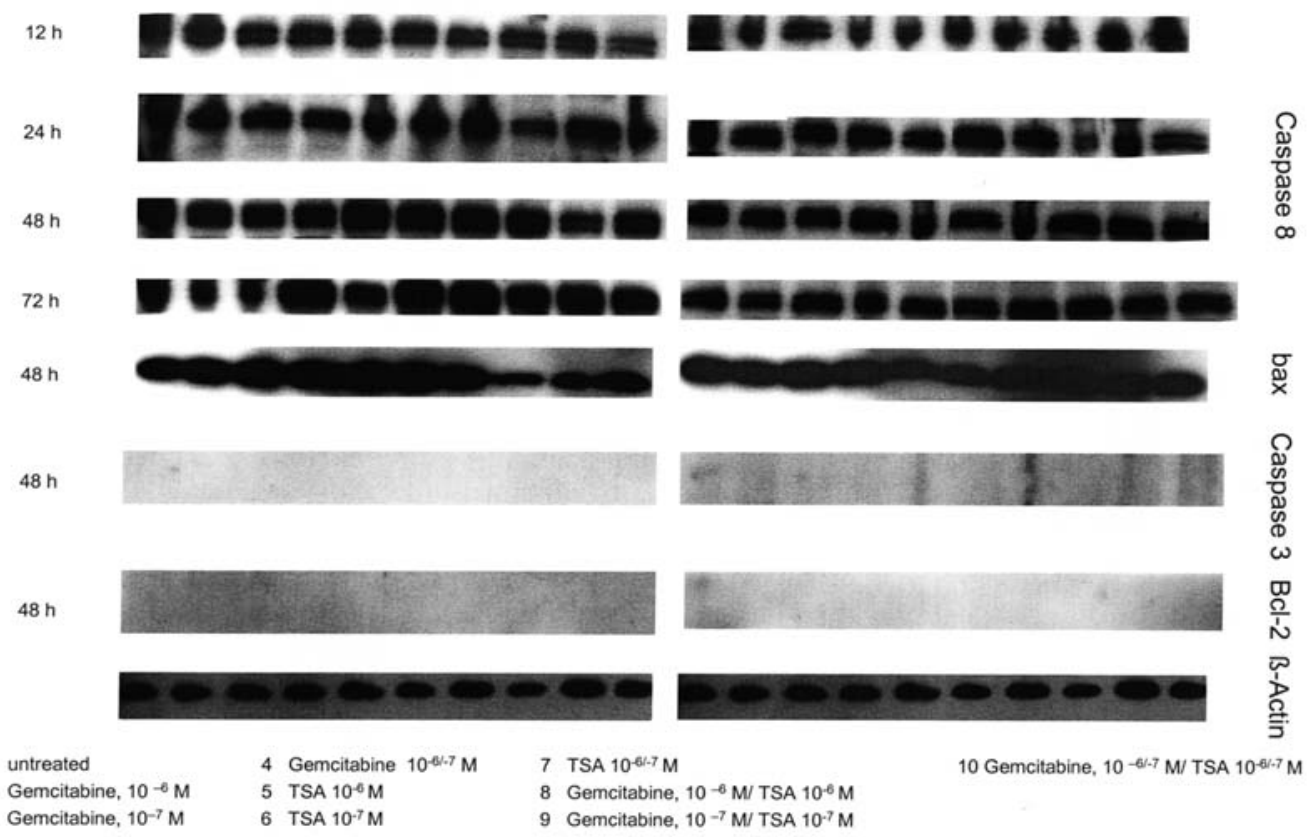

Figure 7. Western blot analysis of DANG and PANC-89 treated with different concentrations of TSA and gemcitabine alone or in combination for $12,24,48$ and $72 \mathrm{~h}$. Samples were probed with antibodies against bax, bcl-2, caspase-3, caspase-8 and B-actin as standard to show equal loading of lanes. No expression could be observed of bcl-2 and caspase-3. Expression of caspase- 8 increased up to $72 \mathrm{~h}$. Representative data of bax, caspase-3 and bcl-2 are given for $48 \mathrm{~h}$ time-point. 


\section{YAP C}
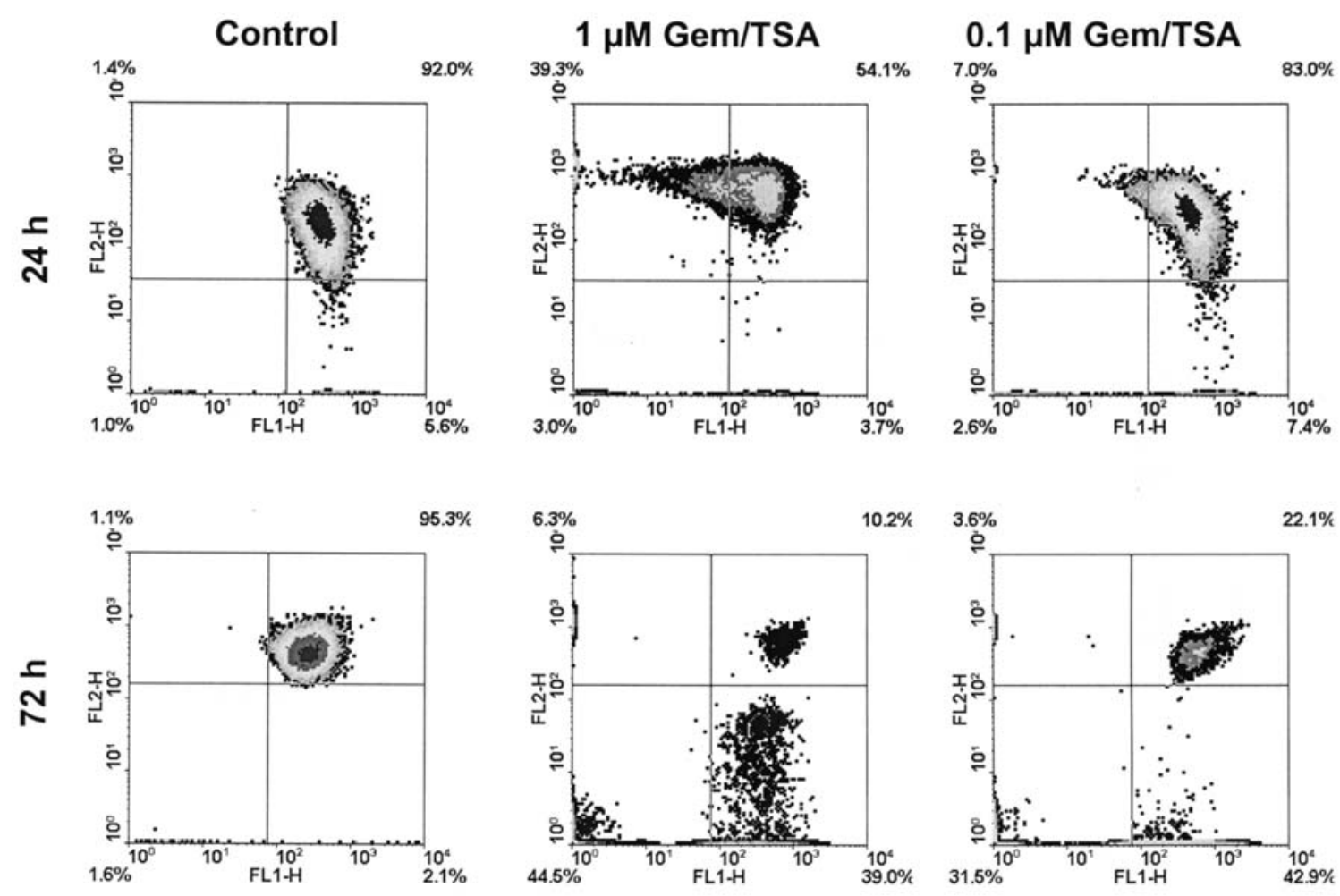

Figure 8. JC-1 staining of the mitochondrial potential $\Delta \Psi_{\mathrm{m}}$. Shown are representative examples of YAPC cells treated with $1 \mu \mathrm{M}$ gemcitabine/TSA and $0.1 \mu \mathrm{M}$ gemcitabine/TSA for 24 and $72 \mathrm{~h}$ and untreated controls at 24 and $72 \mathrm{~h}$. Quadrant analysis of 10,000 acquired events, gated for cell viability, was performed to determine the percentage of cells stained positive for monomeric (green fluorescence detector FL1-H, $\mathrm{x}$-axis) as well as dimeric JC-1 (red fluorescence detector FL2-H, y-axis).

time-dependently to 83 and $22 \%$ after 24 and $72 \mathrm{~h}$, respectively. This effect was increased at a combination of $10^{-6} \mathrm{M}$ gemcitabine and $10^{-6} \mathrm{M}$ TSA: after $24 \mathrm{~h} 54 \%$ cells contained intact mitochondria, whereas after 72 h only $10 \%$ intact mitochondria remained. Similar results were shown in the other cell lines (data not shown). These values correlated significantly with apoptosis induction as determined by propidium iodide staining with a Spearman's correlation coefficient $\left(\mathrm{R}^{2}\right)$ of 0.7 and were conformed in the other cell lines (data not shown).

\section{Discussion}

Chemotherapy options for advanced or metastatic pancreatic cancer are limited and an efficient and well tolerated therapy is urgently needed. Most of the studies with single chemotherapeutic agents in pancreatic cancer led to low responses rates and had only a slight impact on survival. Gemcitabine as single agent is established as the reference treatment in advanced or metastatic cancer (2). However, clinical efficacy with gemcitabine as a single agent remains poor, although it improves the quality of life. gemcitabine-based combinations are needed to improve outcomes.

We showed that exposure of YAPC, DANG and PANC-89 pancreatic adenocarcinoma cells to the combination of gemcitabine and TSA effectively caused a suppression of DNA synthesis (Fig. 4) and induction of apoptosis (Fig. 1C).
Furthermore, combination of these agents had an overadditive anti-tumoral efficacy (Fig. 1). These effects confirm the results of Piacentini et al (10). The main effect of inducing cell apoptosis must be the efficacy of TSA, because TSA as single agent leads to a higher rate of apoptosis than gemcitabine as single agent in equal concentrations, e.g. in a concentration of $10^{-6} \mathrm{M}$ (Fig. 1). Besides, there is supposed to be a synergistic effect of gemcitabine and TSA, because gemcitabine leads to a $G_{1}$ arrest, whereas TSA induces an arrest in the $\mathrm{G}_{2} / \mathrm{M}$-phase. This is of particular interest, since in vivo the monotherapies were ineffective. The effect was not seen in foreskin fibroblasts, which were used as controls. The effect of TSA as a sensitizer for chemotherapy in pancreatic cancer cell lines was recently shown (10), however, mechanistic aspects were not explored.

Gemcitabine inhibits the synthesis of DNA by incorporation of its triphosphorylated metabolite difluorodeoxycytidine triphosphate into DNA. After incorporation into DNA, a second nucleotide is incorporated into DNA that masks gemcitabine from the DNA excision repair mechanism. Thus, gemcitabine acts as a chain terminator (16). Recently the apoptotic effect of gemcitabine on pancreatic cancer cells was reported again (17). Cell growth of the pancreatic cancer cell line PANC-1, was inhibited time- and dose-dependently by gemcitabine. This confirms our results, because we were able to show, that our cancer cell lines YAPC, DANG and PANC-89 are 
inhibited in a time- and dose-dependent manner by gemcitabine, which leeds to inhibition of cell proliferation and induction of apoptosis.

TSA induces apoptosis and inhibits proliferation in several tumor types, for example in hepatoma cells (4), malignant cerebral (18) and kidney cells (19). Acetylation of lysine residues decreases the positive charge at the $\mathrm{N}$-terminal tail domains of histones and weakens their interaction with DNA $(9,20)$. This allows transcription factors to bind to DNA and to initiate the transcriptional machinery, which leeds to an increased apoptosis and inhibition of cell proliferation (8). In consequence the different mechanisms of TSA and gemcitabine lead to a synergistic effect of both: while TSA develops its maximal effect in the $\mathrm{G}_{2} / \mathrm{M}$-phase and leads to a cell cycle arrest, gemcitabine extends its effect in the $G_{1}$ phase.

In our experiments with pancreatic adenocarcinoma cells, YAPC, DANG and PANC-89 jointly up-regulated proapoptotic bax in a time-dependent manner (Fig. 7). Caspase-8 levels were constantly expressed in all tested adenocarcinoma cell lines (Fig. 7). The results of the caspase assays (Fig. 6) confirmed the results of inhibiting cell proliferation (Fig. 4): an increase of activity of caspase- 8 was seen at a combination of lower concentrations of TSA and gemcitabine $\left(10^{-7} \mathrm{M}\right)$. In DANG and Panc-89 cells the activation of caspase- 8 must be before $24 \mathrm{~h}$ for a very short time, because after $24 \mathrm{~h}$ nearly no activation of caspase- 8 is seen (Fig. 5). However, the Western blot analysis showed a constant expression of caspase- 8 . So, caspase- 8 must be involved in the cascade of signal-transduction after treatment with gemcitabine and TSA. The increased activity of caspase- 8 in YAPC cells confirms this.

The expression of anti-apoptotic bcl-2, similar to caspase-3, could not be seen. Caspase-3 normally is activated during the process of apoptosis and is one of the key enzymes required for the execution of the apoptotic programme. Caspase- 8 (the major caspase to be activated by the TNF pathway) is one of the initiator-caspases activating the downstream effector-caspases, especially caspase-3. Our results show a constant expression of caspase- 8 in all pancreatic cancer cell lines (Fig. 7), while caspase-3 was not expressed in the Western blot analysis, but a high activity of caspase-3, especially in YAPC cells, was observed. While the main activity in YAPC cells was seen after $72 \mathrm{~h}$, in PANC-89 cells the increased activity was observed after $24 \mathrm{~h}$. The activation of caspase- 3 after $72 \mathrm{~h}$ in DANG cells was low. Compared to the results of the Western blot analysis there was supposed to be a very high consumption of caspase-3, because the expression of caspase F3 is not seen in the Western blot analysis. However, activity of caspase- 3 was demonstrated. Therefore, further evaluation is necessary.

Our results of expression of caspase- 8 and bax in the Western blot analysis and the increased activity of caspase- 3 demonstrate that TSA and gemcitabine induce the membranerelated as well as the mitochondrial apoptosis pathway.

We conclude that in contrast to monotherapy a combination of gemcitabine and TSA is effective in stopping proliferation and in enhancing apotosis in human pancreatic cancer cells in vitro. The combination of TSA and gemcitabine acts synergistically. Since combinations allow the use of lower concentrations of agents than monotherapy, maximal antitumoral efficacy in vivo without causing major side effects is expected. We also showed the mechanistic aspects involved in the signal transduction proteins caspase- 3 , caspase -8 and bax.

\section{Acknowledgements}

This study was supported by grants from the ELAN-Program (Fund for Research and Teaching, University of ErlangenNuernberg) (Project 04.09.17.1).

\section{References}

1. Society AC: Cancer Facts and Figures 2004. American Cancer Society, Atlanta, 2004.

2. Burris HA, III, Moore MJ, Andersen J, Green MR, Rothenberg ML, Modiano MR, Cripps MC, Portenoy RK, Storniolo AM, Tarassoff P, Nelson R, Dorr FA, Stephens CD and von Hoff DD: Improvements in survival and clinical benefit with gemcitabine as first-line therapy for patients with advanced pancreas cancer: a randomized trial. J Clin Oncol 15: 2403-2413, 1997.

3. Shin JY, Kim HS, Lee KS, Kim J, Park JB, Won MH, Chae SW, Choi YH, Choi KC, Park YE and Lee JY: Mutation and expression of the p27KIP1 and p57KIP2 genes in human gastric cancer. Exp Mol Med 32: 79-83, 2000.

4. Herold C, Ganslmayer M, Ocker M, Hermann M, Geerts A, Hahn EG and Schuppan D: The histone-deacetylase inhibitor trichostatin A blocks proliferation and triggers apoptotic programs in hepatoma cells. J Hepatol 36: 233-240, 2002.

5. Schmidt K, Gust R and Jung M: Inhibitors of histone deacetylase suppress the growth of MCF-7 breast cancer cells. Arch Pharm 332: 353-357, 1999.

6. Csordas A: On the biological role of histone acetylation. Biochem J 265: 23-38, 1990.

7. Medina V, Edmonds B, Young GP, James R, Appleton S and Zalewski PD: Induction of caspase-3 protease activity and apoptosis by butyrate and trichostatin A (inhibitors of histone deacetylase): dependence on protein synthesis and synergy with a mitochondrial/cytochrome c-dependent pathway. Cancer Res 57: 3697-3707, 1997.

8. Gray SG, Kytola S, Lui WO, Larsson C and Ekstrom TJ: Modulating IGFBP-3 expression by trichostatin A: potential therapeutic role in the treatment of hepatocellular carcinoma. Int J Mol Med 5: 33-41, 2000.

9. Hoshikawa Y, Kwon HJ, Yoshida M, Horinouchi S and Beppu T: Trichostatin A induces morphological changes and gelsolin expression by inhibiting histone deacetylase in human carcinoma cell lines. Exp Cell Res 214: 189-197, 1994.

10. Piacentini P, Donadelli M, Costanzo C, Moore PS, Palmieri M and Scarpa A: Trichostatin A enhances the response of chemotherapeutic agents in inhibiting pancreatic cancer cell proliferation. Virchows Arch 448: 797-804, 2006.

11. Ocker M, Alajati A, Ganslmayer M, Zopf S, Luders M, Neureiter D, Hahn EG, Schuppan D and Herold C: The histonedeacetylase inhibitor SAHA potentiates proapoptotic effects of 5 -fluorouracil and irinotecan in hepatoma cells. J Cancer Res Clin Oncol 131: 385-394, 2005.

12. Smiley ST, Reers M, Mottola-Hartshorn C, Lin M, Chen A, Smith TW, Steele GD Jr and Chen LB: Intracellular heterogeneity in mitochondrial membrane potentials revealed by a J-aggregate-forming lipophilic cation JC-1. Proc Natl Acad Sci USA 88: 3671-3675, 1991.

13. Mancini M, Anderson BO, Caldwell E, Sedghinasab M, Paty PB and Hockenbery D M: Mitochondrial proliferation and paradoxical membrane depolarization during terminal differentiation and apoptosis in a human colon carcinoma cell line. J Cell Biol 138: 449-469, 1997.

14. Legrand O, Perrot JY, Simonin G, Baudard M and Marie JP: JC-1: a very sensitive fluorescent probe to test Pgp activity in adult acute myeloid leukemia. Blood 97: 502-508, 2001.

15. Leers MP, Kolgen W, Bjorklund V, Bergman T, Tribbick G, Persson B, Bjorklund P, Ramaekers FC, Bjorklund B, Nap M, Jornvall $\mathrm{H}$ and Schutte $\mathrm{B}$ : Immunocytochemical detection and mapping of a cytokeratin 18 neo-epitope exposed during early apoptosis. J Pathol 187: 567-572, 1999. 
16. Huang P, Chubb S, Hertel LW, Grindey GB and Plunkett W: Action of 2',2'-difluorodeoxycytidine on DNA synthesis. Cancer Res 51: 6110-6117, 1991.

17. Jiang PH, Motoo Y, Sawabu N and Minamoto T: Effect of gemcitabine on the expression of apoptosis-related genes in human pancreatic cancer cells. World J Gastroenterol 12: 1597-1602, 2006.

18. Wang ZM, Hu J, Zhou D, Xu ZY, Panasci LC and Chen ZP. Trichostatin A inhibits proliferation and induces expression of p21WAF and p27 in human brain tumor cell lines. Ai Zheng 21: 1100-1105, 2002

19. Park WH, Jung CW, Park JO, Kim K, Kim WS, Im YH, Lee MH, Kang WK and Park K: Trichostatin inhibits the growth of ACHN renal cell carcinoma cells via cell cycle arrest in association with p27, or apoptosis. Int J Oncol 22: 1129-1134, 2003.
20. Saito A, Yamashita T, Mariko Y, Nosaka Y, Tsuchiya K, Ando T, Suzuki T, Tsuruo T and Nakanishi O: A synthetic inhibitor of histone deacetylase, MS-27-275, with marked in vivo antitumor activity against human tumors. Proc Natl Acad Sci USA 96: 4592-4597, 1999

21. Gray SG and Ekstrom TJ: Effects of cell density and trichostatin $\mathrm{A}$ on the expression of HDAC1 and p57Kip2 in Hep 3B cells. Biochem Biophys Res Commun 245: 423-427, 1998. 